\title{
Type 2 Diabetes Mellitus in Children and Adolescents: An update
}

\author{
UHBEGUM $^{\mathrm{a}}$, MA RAHMAN ${ }^{\mathrm{b}}$
}

\begin{abstract}
Summary:
Childhood type 2 Diabetes Mellitus (DM) has increasingly been reported worldwide. It is commonly associated with childhood obesity.It may be presented with classical manifestation of DM such as polyuria, polydipsia, weight lossor acute complications like Diabetic ketoacidosis (DKA), Hyperglycemic Hyperosmolar State (HHS) or features of insulin resistance syndrome. Many a cases it may remain asymptomatic and hence undiagnosed.So,overweight children and adolescents who met screening criteria such as family history of type 2 DM, signs of insulin resistance, and high risk ethnics should undergo screening. Emphasis should be given on early diagnosis and optimum management plan to avoid grave consequences of it in early part of life. Diagnosis of type 2 Diabetes Mellitus in children should be done on the basis of standard diagnostic criteria such as American Diabetic Association (ADA) criteria. Both non-pharmacological and drug management are important equally. Multidisciplinary
\end{abstract}

\section{Introduction:}

Type 2 diabetes mellitus(DM) happens when the body cannoteffectively use the insulin it produces. Formerly, it was called non-insulin dependent or adult onset diabetes mellitus as because, for many years it was seen only in adults.In type 1 diabetes mellitus, the body does not produce insulin and it is usually diagnosed in children and young adults. Recently,type 2 diabetes mellitushas increasingly been reported in children and

a. Dr Most. Umme Habiba Begum, Associate Professor, Department of Pediatrics, Rangpur Community Medical College, Rangpur.

b. Dr Lt Col Md. Anisur Rahman, Specialist Medical Officer (Medicine), Combined Military Hospital (CMH), Rangpur.

Address of Correspondence: Dr Most. Umme Habiba Begum, Associate Professor, Department of Pediatrics, Rangpur Community Medical College, Rangpur. e-mail: uhabibarp27@gmail.com, arafanis@gmail.com Mobile: $01712546647,01521248085$.

Received: 1 May 2016

Accepted: 6 Dec. 2016 team approach including self-management plan is mandatory for obtaining optimal therapeutic goals of type 2 DM in children and adolescents. Lifestyle modification, dietary intervention, weight reduction, patient education, psychological support, and oral anti diabetic drugs and insulin therapy should be included in comprehensive diabetic management plan. Complications of type 2 DM should be minimized by all means with strict glycemic control and management of co-morbidity if any. Emphasis should also be given on prevention of type $2 \mathrm{DM}$ by adopting a healthy lifestyle characterized by healthy eating behavior, regular physical activity and subsequent modest weight loss that can prevent the progression of impaired glucose tolerance to clinical diabetes mellitus.

Key words:American Diabetic Association (ADA), Diabetic Ketoacidosis (DKA), Hyperglycemic Hyperosmolar State (HHS), Overweight, Type 2 Diabetes Mellitus (DM).

(J Bangladesh Coll Phys Surg 2017; 35: 24-30)

adolescents, so much so that in some parts of the world type 2 diabetes has become the main type of diabetes in children. The global rise of childhood obesity and physical inactivity is widely believed to play a crucial role $^{1}$. Currently, more than 200 children and adolescents develop the disease every day worldwide ${ }^{2}$. But healthy eating and lifestyle habits are a strong defense against the disease.

Risk factors and PathophysiologyofType 2 DM:

Type 2 DMis a complex metabolic disorder of heterogeneous etiology with social, behavioral, and environmental risk factors unmasking the effects of genetic susceptibility ${ }^{3}$. There is a strong hereditary component of the disease. The major risk factors of type 2 DM in children are: obesity and inactivity, family history of type 2 DM, age of 12-16 years, maternal gestational diabetes or type 2 diabetes, not breast feeding during infancy and ethnicity. Other factors that appear to increase risk include poor fetal growth, low birth weight and high birth weight ${ }^{4}$. Impaired glucose 
homeostasis is the key mechanism in type $2 \mathrm{DM}$ and it depends on the balance between insulin secretion by the pancreatic â- cells and insulin action. The mean age range of onset of type 2 diabetes in youths coincides with the relative insulin resistance that occurs during pubertal development, resulting in hyper-insulinemia and play a major role in the development of type $2 \mathrm{DM}$ in children and adolescents. The adverse effect of obesity on glucose metabolismis evident early in childhood. Obese children arehyper-insulinemicand have approximately $40 \%$ lower insulinstimulatedglucose metabolism compared with non-obesechildren ${ }^{5}$.

\section{Epidemiology of Type $2 \mathrm{DM}$ in children and adolescents:} Type $2 \mathrm{DM}$ in youth appears to be emerging as a seriousclinical issue. It's prevalence in the United States (USA) is approximately 12:100000, while it is still rare in Europe $^{6}$ (approx.,2.5:100000). In Bangladesh the exact prevalenceof Type $2 \mathrm{DM}$ is not known. But in a studyamong 2152 students volunteers inBangladesh, Abu Sayeedet $\mathrm{al}^{7}$. observedthat the prevalence of type $2 \mathrm{DM}$ and impaired fasting glucose (IFG)appears to be $1.8 \%$ and $3.4 \%$ respectively. The majority of USA young peoplediagnosed with type 2 diabetes are found inspecific ethnic subgroups such as AfricanAmerican,Hispanic, Asian/Pacific Islanders and American Indiansbeing highest in Pima Indians (22.3/ 1000 in 10-14 yearold children). Furthermore, the great majorityof the children are obese. Screening studies in obeseadolescents have reported a prevalence of $0.4 \%$ up to $1 \%$ of type 2 diabetes in obese children e" 12 years 8 .

\section{Clinical presentationof Type 2 DM:}

The presentation of type 2 DMin children and adolescents varies according to the disease stage. Early in the disease, before diabetes diagnostic criteria are met, insulin resistance predominates with compensatory high insulin secretion, resulting in normoglycemiaand the patient likely to be asymptomatic ${ }^{9}$. At this stage, the disease may only be detected by abnormal blood glucoseconcentrations identified during screening. Obesity is the hallmark of type 2 diabetes in children and adolescents.Most children are obese orextremely obese at diagnosis and present with glycosuriawithout ketonuria, absent or mild polyuria and polydipsia,and little or no weight loss. In its severest form, the child presents with polyuria,polydipsia, and weight loss. Up to $33 \%$ in particularethnic groups have ketonuria at diagnosis and 5\%-25\%ketoacidosis at presentation ${ }^{10}$. Vary rarely, type 2 diabetes mellitus manifest with a hyperglycemichyperosmolarstate (HHS). Acanthosisnigricans and polycystic ovarian syndrome (PCOS), disorders associated with insulin resistance and obesity, are common in youth with type $2 \mathrm{DM}^{11}$. Children with type 2 diabetes frequently have a positive family history, and $74 \%-100 \%$ first or second degree relative have type 2 DM. Some syndromes such as Klinefelter syndrome, BardetBiedl Syndrome, PraderWilli Syndrome and Alström Syndrome are also associated with type 2 DM. They all are associated with mental retardation and frequently to extreme obesity ${ }^{12}$.

\section{Differential Diagnosis:}

Patients with type $2 \mathrm{DM}$ may have clinicalpresentations indistinguishable from those of patientswith other types of diabetes mellitus ${ }^{11}$. It is important to classify diabetes mellitus in children and adolescents correctly, sothat appropriate therapy may be instituted. Typically, children with type 1 diabetes mellitus are not overweight and have recent weight loss, polydipsia, and polyuria. They have a short duration ofsymptoms and frequently have ketoacidosis at presentation ${ }^{11}$.Type 2 diabetic children and adolescents may represent a form of earlyonset latent autoimmune diabetes mellitus similar to that described in adults (LADA). These Patients with LADA share insulin resistance with that of type 2 diabetes mellitus patients but display a more severe defect in âcell capacity ${ }^{12}$. Following the terminology 'latent autoimmune diabetes mellitus in adulthood, LADA', the non-insulin dependent diabetic children and adolescents with â-cell autoantibodies could be named 'latent autoimmune diabetes mellitus in youth' $(\text { LADY })^{13}$. Double diabetes mellitus or type 1.5 diabetes mellitus are other proposed names for this entity ${ }^{13}$. Maturity-onset of diabetes mellitus of the young(MODY) is another rare form of diabetes mellitus inchildren that includes several disorders caused by monogenicdefects in â-cell function ${ }^{14}$. MODY 2 and MODY 3 (defect in glucokinase and HNFlá respectively) are themost frequent types of MODY. Patients with MODYhave a dominant genetic traits, usually are nonobese andhave low fasting insulin levels. Recent studies suggestthat the clinical presentation of MODY is broad, rangingfrom asymptomatic hyperglycemia to a severe acutepresentation ${ }^{13}$. 


\section{Diagnostic criteria for Type 2 Diabetes Mellitus:}

Diagnosis of type 2 Diabetes Mellitus in children and adolescents can be made on the basis ofAmerican Diabetic Association(ADA)revised diagnostic criteria (Table 1$)^{15}$ or any other diagnostic criteria. In the absence of unequivocal hyperglycemia, random, fasting or twohoursblood sample should be confirmed by repeat testing.Other tests may be necessary in difficult cases for diagnosis of type of DM, such as fasting insulin or $\mathrm{C}$-peptide determination and occasionally, $\beta$-cell autoantibodies measurements. C-peptide levels are elevated in individuals with type 2 diabetes mellitus in contrast to patients with type 1diabetes mellitus or MODY diabetes.

\section{Table-I}

\section{Diagnostic criteria for type $2 \mathrm{DM}^{15}$}

- Symptoms of diabetes mellitus such as polydipsia, polyuria, and unexplained weight loss plus

- $\quad$ Random glucose concentration $\geq 200 \mathrm{mg} / \mathrm{dL}$ (11.1 $\mathrm{mmol} / \mathrm{L}$ ) in venous plasma,

- $\quad$ Fasting glucose $\geq 126 \mathrm{mg} / \mathrm{dL}(7.0 \mathrm{mmol} / \mathrm{L})$ in venous or capillary plasma,

- Or two-hours glucose during oral glucose tolerance test (oGTT) $\geq 200 \mathrm{mg} / \mathrm{dL}(11.1 \mathrm{mmol} / \mathrm{L})$ in venous plasma or capillary whole blood sample And

- Hemoglobin A1c $(\mathrm{HbA} 1 \mathrm{c}) \geq 6.5 \%$

\section{Screening for Type 2 Diabetes Mellitus:}

Most of the children and adolescents with type 2 diabetes remain asymptomatic at diagnosis. So screening for it is necessary ${ }^{16}$.It is found that unrecognized hyperglycemiacontributes to both microvascular and macrovascular risk in later life ${ }^{17}$. However, at the present time, a general screening for type $2 \mathrm{DM}$ in youth is unlikely to be costeffective and so a targeted screening is necessary. The ADA recommends a screening in overweight children and adolescents at onset of puberty in high risk patients (Table 2). Screening test should be performed every 2 years starting at the age of 10 years or at onset of puberty. It should be done by testing fasting glucose or $\mathrm{oGTT}^{18}$.
Table-II

Criteria for screening tests for type $2 \mathrm{DM}$ in children and adolescents ${ }^{18}$

$\overline{\text { Overweight }(\mathrm{BMI}>90 \text { percentile) plus one of the }}$ following risk factors:

- $\quad$ Family history of type $2 \mathrm{DM}$ in $1^{0}$ or $2^{0}$ relative;

- Race/ethnicity (Asian, American Indian, AfricaAmericans, Hispanics);

- Signs of insulin resistance; or conditions associated with insulin resistancesuch as acanthosisnigricans, hypertension, dyslipidemia, polycystic ovarian syndrome (PCOS);

- $\quad$ Extreme obesity (BMI $>99.5$ percentile).

\section{Complications of Type 2 Diabetes Mellitus:}

The chronic complications of type 2 DM in children and adolescents are macrovasculardiseases like accelerated developmentof cardiovascular disease leading to stroke andmyocardial infarction, and microvascular diseases likenephropathy, retinopathy and neuropathy leading toend-stage renal disease, loss of visual acuity, and limbamputations. Microvascular disease is the hallmark of hyperglycemia diagnosed at a younger age. As becausethe complications of DM are related to the duration of disease itself, risksof complications more common in children and adolescents as compared to adult diabetics ${ }^{19}$.All of these complications contribute tothe excess morbidity and mortality in individuals withdiabetes mellitus.Youngpeople with type 2 DM appear to be at amuch higher risk of developing early diabetes associated complications than those with type 1 diabetesMellitus ${ }^{20}$. This higher level of risk does not appear to berelated to overall levels of glycemic control or durationof disease but to occurrence of hypertension and dyslipidemia.

\section{Management of Type 2 Diabetes Mellitus:}

The idealgoalof management(Table 3$)^{21}$ of type 2 diabetes inchildren and adolescents is normalization of blood glucose values, HbAlc and to decrease the risk of diabetes related acute and chronic complications. Successful control of the associatedcomorbidities, such as hypertension and dyslipidemia, isalso important ${ }^{11}$. The American Academy of Pediatrics has, very recently, 
published the management guidelines for children and adolescents with type 2 diabetes mellitus ${ }^{22}$.

Table-III

Therapeutic goal of type 2 DM in children and adolescents $^{21}$

- Before breakfast sugar: $90-130 \mathrm{mg} / \mathrm{dL} \mathrm{(5.0-7.2}$ $\mathrm{mmol} / \mathrm{L}$ );

- Before bed/ overnight sugar $90-150 \mathrm{mg} / \mathrm{dL}(5.0$ $8.3 \mathrm{mmol} / \mathrm{L})$;

- $\quad$ Target $\mathrm{HbA} 1 \mathrm{C}<7 \%$;

- Target blood pressure consistently, $<90$ th percentile for age, sex, and height;

- Target LDL cholesterol value, $100 \mathrm{mg} / \mathrm{dL}$ $(2.6 \mathrm{mmol} / \mathrm{L})$.

Insulin therapy should be initiated for children and adolescents with type 2DM who are ketotic or in diabetic ketoacidosis and in whom the distinction between type 1 and type 2DM is unclear; and, in usual cases: who have random venous blood orplasma sugar concentrationse" $250 \mathrm{mg} / \mathrm{dL}$; orwhose HbAlc is $>9 \%$.In all other instances, lifestyle modification program, including nutrition and physical activity, and Metformin should be started as first-line therapy atthe time of diagnosis of type $2 \mathrm{DM}^{22}$. Despite of severe manifestation, initial management of obese children and adolescents with type $2 \mathrm{DM}$ should consist of behavior modification strategies for lifestyle change such as decreasing high-caloric high-fat food choice and sedentary behavior, while increasing physical activity. Lifestyle changes should not be imposed and selfmotivation is necessary ${ }^{23}$.Treatmentoptions of type 2 DM include:

Diet: Balanced macronutrient diets at 900 to $1200 \mathrm{kcal}$ per day are associated with both short and long-term (e"1 year) improvements in weight status and body composition in children 6 to 12 years of age ${ }^{24}$. These calorie management are to be incorporated with lifestyle changes, including increased activity and medication. Restrictions of no less than $1200 \mathrm{kcal}$ per day in adolescents 13 to 18 years old result in improved weight status and body composition ${ }^{25}$.

Physical activity:It is an integral part of weight management for prevention and treatment of type 2DM.
Children and adolescents are encouraged to engage in 'moderate-to-vigorous' exercise for at least 60 minutes daily and to limit non-academic 'screen time' to less than 2 hours a day. Screen time contributes to a sedentary lifestyle, especially when the child or adolescent eats while watching television or playing computer games $^{26}$.

Patients education:All children with type 2 diabetes mellitus should receive comprehensive self-management education which include teaching self-monitoring of blood glucose,performed as needed and during periods of acute illness or when symptoms of hyper- or hypoglycemia occur ${ }^{27}$.

Pharmacological treatment:If treatment goal with nutrition education and exercise is not met, pharmacological therapy is indicated. Metformin andinsulin are the only anti-diabetic agentscurrentlyrecommended for use inchildren. Thiazolidinediones andincretins are occasionally used inadolescents younger than 18 years ${ }^{28}$.Metformin, a biguanide, is the most appropriatestarting point for pharmacological treatmentin children with type 2 diabetes mellitus if insulin therapy is not indicated. The effectivenesshas been proven for adolescents in clinical trials. Metformin decreases hepatic glucoseoutput and enhances primarily hepatic and also muscleinsulin sensitivity without a direct effect on â-cell function.It has the advantage of weight reduction, decrease in lipids without the risk of hypoglycemia.Because of concerns about lactic acidosis metformin iscontraindicated in patients with impaired renal function and should be discontinued with the administration ofradiocontrast material or hypocaloric diet. Metforminshould not be used in patients with known hypoxemicconditions, severe infection, hepatic disease, or alcoholabuse. The most common side effects of metformin aregastrointestinal disturbances. The dose of metforminshould be increased up to $2 \mathrm{gm}$ in split doses, unless thereare gastrointestinal side effects. Metformin has a goodsafety record, but should not be given if there is anydoubt at all about the nature of diagnosis.Rosiglitazone, a thiazolidinedione hasbeen studied in some randomized trial in adolescents comparedto lifestyle intervention and metformin and found some effects. However,rosiglitazone has been withdrawn from the market due toits side effects and is not available any more ${ }^{13}$. 
If monotherapy with metformin is not successful over a reasonable period of time (3-6 months), insulin treatment will often be the only feasible way of controlling hyperglycemia. There is no specific contraindication to insulin in children. Any type of insulin and analogs can be used. Insulin regimes should be adopted that are carefully tailored to lifestyle such as bedtime insulin alone, twice-a-day insulin or multidose insulin regimes ${ }^{13}$. Basal insulin is provided through either the use of long acting, relatively peak-free insulin by needle or via an insulin pump. Bolus insulin doses are given at meal-time, using one of the rapid-acting insulin analogs. The bolus dose is calculated by using a correction algorithm for the premeal blood sugar concentration as well as a "carb ratio," in which 1 unit of a rapid-acting insulin analog is given for " $\mathrm{X}$ " grams of carbohydrates ingested (For example, see Table 4) ${ }^{15}$.

\section{Table-IV}

Calculation of Basal Bolus Insulin Regimen ${ }^{15}$

- If an adolescent has a blood glucose of $250 \mathrm{mg} / \mathrm{dL}$, is to consume a meal containing $60 \mathrm{gm}$ of carbohydrates, with a carbohydrate ratio of $1: 10$ and an assigned correction dose of 1:25>125 the mealtime bolus dose of insulin would be as follows: $60 \mathrm{gm} / 10=6$ units rapid-acting insulin for meal plus

$(250-125) / 25=125 / 25=5$ units rapid-acting insulin for correction; Thus, total bolus insulin coverage at mealtime is: 11 Units $(6+5)$

- Note: Insulin sensitivity-25; Target blood glucose level-125mg/dl, 'carb ratio'-10.

\section{Monitoring of Diabetes Mellitus and treatment of complications:}

All children and adolescents with newly diagnosed type $2 \mathrm{DM}$, regardless of prescribed treatment plan, should perform finger-stick blood glucose monitoring before meals and at bedtime until reasonable metabolic control is achieved ${ }^{29}$. Once blood glucose concentrations are at target levels, the frequency of monitoring can be modified depending on the medication used, the regimen's intensity, and the patient's metabolic control.Monitoring of $\mathrm{HbA} 1 \mathrm{c}$ concentrations every 3 months andintensification of treatment is required if treatment goals forblood sugar and $\mathrm{HbAlc}$ concentrations are not being met.Patients on insulin should also be monitored periodically for asymptomatichypoglycemia. To monitor retinopathy, dilated eye examinations should be performed regularly. Screening for microalbuminuria should be performed yearly ${ }^{26}$. Angiotensin converting enzyme(ACE) inhibitors are the agents of choice in children with microalbuminuria. Control of hypertension in children with type 2 diabetes mellitus is mandatory. If normotension is not achieved by ACE inhibitors, combination therapy with $\alpha$-blockers, calcium antagonists or low-dose diuretics may be needed. It is unclear whether foot examinations are important in children. Testing for and treating lipid abnormalities are necessary to avoid macrovascularcomplications ${ }^{30}$.

\section{Psychological impacts of Type 2 DM in children and adolescents:}

Adolescents with type 2 diabetes mellitus rate lower 'Quality of Life' scores than their peers with type1 DM and the burden ofneuropsychiatricdisorders in young people with type 2 DMis high, with as many as one in five experiencing eitherpsychiatric illness or neuro developmental/behavioral problems. It is found that psychosocial factors representa significant barrier to optimum self-management inadolescents with type DM, often leadingto a vicious circle of spiraling poor selfmanagementand increasing psychosocial problems.Poor psychosocial health may also be physiologically related to poorer glycemic control. Therefore psychologists should be the core component of care of children and adolescents with type 2 diabetes mellitus ${ }^{13}$.

\section{Prevention of Type 2 Diabetes Mellitus:}

Prevention of Type 2 Diabetes Mellitus should startvery early in life, even before birth. Primary prevention has proven to be difficultor impossible in most societies. A multidisciplinaryteam approach is needed to develop and securepreventive strategies. Good nutrition and modest exercisefor pregnant women as well as monitoring of intrauterinegrowth of the fetus are mandatory. After birth,rapid weight gain should be avoided and the principlesof good nutrition and physical activity are to be taught at allages. Breastfeeding should be strongly recommended.Children's food choice can be influenced by early interventionand guidance $^{18}$.Teacher training, modificationof school meals and physical education are effectivein reducing 
risk factors for obesity which is the hallmark of type 2 $\mathrm{DM}$ in children.Recent intervention studieshave convincingly demonstrated that adoption of ahealthy lifestyle characterized by healthy eating behavior, regularphysical activity and subsequent modest weight loss canprevent the progression of impaired glucose tolerance toclinical diabetes mellitus. The use of metforminis not effective to preventtype 2 DM inobese adolescents with impaired glucose tolerance ${ }^{31}$.

\section{Conclusion:}

Type 2 diabetes mellitus is emerging as a new clinical problem within pediatric practice. Clinicians should be aware of the frequent mild or asymptomatic manifestation of type 2 diabetes mellitus in childhood. Therefore, a screening seems meaningful especially in high risk groups such as children and adolescents with obesity, relatives with type 2 diabetes mellitus, and clinical features of insulin resistance. Emphasis should be given on early diagnosis and comprehensive management plan to avoid grave consequences of it in early part of life. All efforts should be given on prevention of type 2 DM such as, healthy eating, physical activity, and modest weight reduction. Collaborative efforts from all corners of the modern society can efficiently combat against this emerging disease.

\section{Reference:}

1. World Health Organization (WHO). What are the risks of diabetes in children? Diabetes fact sheet 2016.available at: www.who.int/features/qa/65.

2. Suyanne FM, Márcio FM, Niciane Pessoa BM, Adman Câmara SL,Roberto WF, Marta Maria CD. Risk Factors for Type 2 diabetes mellitus in Children. Rev. LatinoAm. Enfermagem. 2010:18(5):936-42.

3. Kiess W, Böttner A, Raile K, Kapellen T, Müller G, Galler A. Type 2 diabetes mellitus in children and adolescents: a review from a European perspective. Horm Res 2003; 59 (1) $: 77-84$.

4. JohnssonIW, Haglund B, Ahlsson F, Gustafsson J. A high birth weight is associated with increased risk of type 2 diabetes and obesity. PediatrObes. 2015;10(2): 77-83.

5. Weiss R, Dziura J, Burgert TS, Tamborlane WV, Taksali $\mathrm{SE}$, Yeckel $\mathrm{CW}$ et al. Obesity and the metabolic syndrome in children and adolescents. N Engl J Med 2004; 350: 2362-74.

6. Fagot-Campagna A, Pettitt DJ, Engelgau MM, Burrows NR, Geiss LS, Valdez R. Type 2 diabetes among North
American children and adolescents: An epidemiologic review and a public health perspective. J Pediatr 2000; 136:664-72.

7. M. Abu Saeed, Mir Masudur Rahman, Nurrunnhar Fayzunnesa, ParvinAktar Khan, Tanjima Begum, HajeraMahtab et al. Childhood Diabetes in a Bangladeshi Population. J Diabetes Mellitus. 2013;3(1):33-37.

8. Wabitsch M, Hauner H, Hertrampf M, Muche R, Hay B, Mayer H. Type II diabetesmellitus and impaired glucose regulation in Caucasian children and adolescents with obesity living in Germany. Int J ObesRelatMetabDisord 2004; 28: 307-313.

9. Gungor N, Hannon T, Libman I, Bacha F, Arslanian S. Type 2 diabetes mellitus in youth: the complete picture to date. PediatrClin North Am. 2005;52(6):1579-1609.

10. Copeland KC, Zeitler P, Geffner M, Guandalini C, Higgins J, Hirst K. TODAY Study Group. Characteristics of adolescents and youth with recent-onset type 2diabetes: the TODAY cohort at baseline. J ClinEndocrinolMetab. 2011;96(1):159-67.

11. Rosenbloom AL, Silverstein JH, Amemiya S, Zeitler P, Klingensmith GJ. ISPAD Clinical Practice Consensus Guidelines2006-2007. Type 2 diabetes mellitus in the child and adolescent. Pediatr Diabetes 2008; 9: 512-26.

12. Carlsson A, Sundkvist G, Groop L, Tuomi T. Insulin and glucagon secretion in patients with slowly progressing autoimmune diabetes (LADA). J ClinEndocrinolMetab 2000;85: 76-80.

13. Thomas Reinehr. Type 2 diabetes mellitus in children and adolescents. World J Diabetes 2013; 15; 4(6): 270-81.

14. Schober E, Rami B, Grabert M, Thon A, Kapellen T, Reinehr T. Phenotypical aspects of maturity-onset diabetes ofthe young (MODY diabetes) in comparison with Type 2 diabetesmellitus (T2DM) in children and adolescents: experiencefrom a large multicentre database. Diabet Med J 2009; 26: 466-73.

15. American Diabetes Association (ADA). Diagnosis and classification of diabetes mellitus. Diabetes Care 2013; 36(1): s67-s74.

16. Lobstein T, Leach R. Diabetes may be undetected in many children in the UK. BMJ 2004; 328: 1261-62.

17. Arslanian SA. Type 2 diabetes mellitus in children: pathophysiology and risk factors. J Pediatr Endocrinol Metab 2000; 13(6): 1385-94.

18. American Diabetes Association. Type 2 diabetes in children and adolescents. Diabetes Care 2000; 23: 381-9.

19. Hillier TA, Pedula KL. Complications in young adults withearly-onset type 2 diabetes: losing the relative protection ofyouth. Diabetes Care 2003; 26: 2999-3005. 
20. Hagman E, Reinehr T, Kowalski J, Ekbom A, Marcus C, Holl RW. Impaired fasting glucose prevalence in two nationwide cohorts of obese children and adolescents. Int J Obes (Lond) 2014;38(1):40-5.

21. William T. Cefalu; Standards of Medical Care in DiabetesChildren and Adolescents: Diabetes Care 2016;39(1): s86-s93.

22. Springer SC, Silverstein J, Copeland K, Moore KR, PrazarGE, Raymer T. Management of type 2 diabetes mellitusin children and adolescents. Pediatrics 2013; 131: e648-e664

23. Reinehr T. Lifestyle intervention in childhood obesity:changes and challenges. Nat Rev Endocrinol 2013; 9: 607-14.

24. American Dietetic Association. Recommendations summary: pediatric weight management (PWM) using protein sparing modified fast diets for pediatric weight loss. Available at:www.adaevidencelibrary.com:2012.

25. Knowler WC, Barrett-Connor E, Fowler SE,Hamman RF, Lachin JM, Walker EA. Diabetes Prevention Program Research Group. Reduction in the incidence of type 2 diabetes with lifestyle intervention or metformin. N Engl J Med. 2002;346(6):393-403.
26. National Heart, Lung, and Blood Institute, US Department of Health and Human Services, National Institutes of Health. Reduce screen time. Availableat:www. nhlbi.nih. gov/health/public/heart/obesity/wecan/reduce-screen-time/ index.htm. Accessed August 13, 2012.

27. Sabin M. Type 2 diabetes in children. Clinical Obesity 2013; 3:112-6.

28. Rapaport R, Silverstein JH, Garzarella L, Rosenbloom AL. Type 1 and type 2 diabetes mellitus in childhood in the United States: practice patterns by pediatric endocrinologists. J PediatrEndocrinolMetab. 2004; 17(6):871-7.

29. Naughton MJ, Ruggiero AM, Lawrence JM, Imperatore G,Klingensmith GJ, Waitzfelder B. Health-related quality of life of children and adolescents with type 1 or type 2 diabetes mellitus: SEARCH for Diabetes in Youth Study. PediatrAdolesc Med 2008; 162: 649-57.

30. American Diabetes Association. Type 2 diabetes in children and adolescents.Diabetes Care 2000; 23: 381-9.

31. Wiegand S, Allemand D, Hübel H, Krude H, Bürmann M, Martus P. Metformin and placebo therapy both improve weight management and fasting insulinin obese insulinresistant adolescents: a prospective, placebo-controlled, randomized study. Eur J Endocrinol 2010; 163: 585-92. 